\title{
Monitoring resistance of Plasmdium vivax: Point mutations in dihydrofolate reductase gene in isolates from Central China
}

\author{
Fang Huang ${ }^{1}$, Shuisen Zhou ${ }^{*}$, Shaosen Zhang ${ }^{1}$, Weidong Li $^{2}$ and Hongwei Zhang ${ }^{3}$
}

\begin{abstract}
Background: Malaria still represents a significant public health problem in China, and the cases dramatically increased in Central China after 2001. Antifolate resistance in Plasmodium vivax is caused by point mutations in genes encoding dihydrofolate reductase ( $p v d h f r)$ and dihydropteroate synthase (pvdhps). In this study, we used direct sequencing to investigate genetic variation in pvdhfr of malaria patients' samples from Central China.
\end{abstract}

Results: Among all the samples, 21.4\% were wild-type, whereas mutations were detected at three codons $(58,61$ and 117) including single mutant (34.6\%) and double mutants (43.8\%). The most prevalent mutant allele was the one with double mutation at codons 58 and 117 (24.6\%). Three types of single mutation (S58R, T61M and S117N) were found in $2.1 \%, 11.8 \%$ and $20.9 \%$ of parasite isolates, respectively. The four $P$. vivax parasite populations in Central China also differed in pvdhfr allele frequencies.

Conclusions: This study suggested that $P$. vivax in Central China may be relatively susceptible to pyrimethamine. And it also highlights genotyping in the pvdhfr genes remains a useful tool to monitor the emergence and spread of $P$. vivax pyrimethamine resistance.

\section{Background}

Plasmodium vivax is the major cause of malaria outside Africa, mainly in Asia and Americas [1]. Although responsible for less mortality than $P$. falciparum, $P$. vivax causes considerable morbidity, particularly in children [2]. In China a total of 14491 malaria cases and 59741 suspected cases with 12 deaths were reported by the annual case reporting system in 2009 and more than $90 \%$ of the total cases were vivax malaria cases [3]. In Central China, the re-emergence of malaria was considerable in provinces along the Huang-Huai River, especially in Anhui and Henan Provinces. The malaria prevalence increased considerably with the highest incidence and over half of the total malaria cases in 2006 in Anhui Province [4].

\footnotetext{
* Correspondence: ccdczss@sh163.net

${ }^{1}$ National Institute of Parasitic Diseases, Chinese Center for Disease Control and Prevention; WHO Collaborating Centre for Malaria, Schistosomiasis and Filariasia; Laboratory of Parasite and Vector Biology, Ministry of Health,

Shanghai 200025, PR China

Full list of author information is available at the end of the article
}

Since it is difficult to monitor the susceptibility of $P$. vivax to antimalarial drugs by in vitro tests [5], molecular markers of drug resistance are useful tools for mapping the current and changing pattern of pyrimethamine resistance of $P$. vivax isolates. Antifolate resistance is strongly associated with mutations at specific sites in the gene encoding $d h f r$ in malaria parasites [6]. In protozoans, $d h f r$ and thymidylate synthases are parts of a bifunctional enzyme encoded by a single gene. Some research showed that by in vitro assays and kinetic studies of recombinant DHFR enzymes there are several codons that may undergo amino acid substitutions [7-9].

To date, a number of non-synonymous mutations including codons 33, 57, 58, 61, 117 and 173 in the DHFR domain of $P$. vivax, have been reported worldwide [10-17]. These mutant $d h f r$ encode amino acid sequences which are similar to those that cause antifolate resistance in P. falciparum, which suggests that antifolate resistance in $P$. vivax could have arisen in the same manner as that found in P. falciparum. It was also very likely that antifolate-resistant $P$. vivax was selected as a result of heavy deployment of antifolates against 
co-existing falciparum malaria and other infections. While this work was in progress, the kinetic properties of both wild-type and mutant $(\mathrm{S} 58 \mathrm{R}+\mathrm{S} 117 \mathrm{~N})$ recombinant $p v d h f r$ were reported [9]. Mutations in $p v d h f r$ of codons 58 and 117 are considered to be equivalent to pfdhfr mutations at residues 59 and 108, respectively, which are associated with pyrimethamine.

In China, an action plan for malaria elimination was proposed by the Ministry of Health last year. The predominant malaria parasite $P$. vivax in Central China has demonstrated resilience to elimination and become increasingly prevalent in Central China for the past 10 years [18]. With vivax malaria outbreaks occurring frequently in many counties of central provinces in recent years, vivax malaria has become predominant parasite species and is responsible for more than $90 \%$ of malaria cases in China. According to the antimalarial drug policy of China, the first-line therapies for vivax malaria treatment are chloroquine and primaquine, which have been used for more than 60 years, and there is increasing evidence showing the emergence and spread of chloroquine resistance in vivax, especially in Southeast Asia [19].

Most of the studies on antifolate resistance in vivax were performed in regions where vivax and falciparum coexist. Because vivax malaria has not been directly treated with antifolate drugs, the evolution of mutation in the pvdhfr gene could only be inferred from possible selection by treatment of falciparum malaria with antifolate drugs. Until now, mutations in $p v d h f r$ has been studied from limited vivax samples from temperate zone countries, where vivax is the predominant malaria parasite species and has a dramatically different relapse phenotype compared with tropical strains [20]. In the present study, $P$. vivax isolates were collected from four different sites in Central China, and the sequence of the entire $d h f r$ domain was determined to investigate genetic variation in $P$. vivax dihydrofolate reductase.

\section{Methods}

\section{Study area}

In recent years the re-emergence of malaria was considerable in Central China, especially along the HuangHuai River. Four counties in three provinces located in Central China were selected for collecting blood samples (Figure 1). The counties were Huaiyuan and Mengcheng county in Anhui Province, Yongcheng county in Henan Province, Guangshui city in Hubei Province. All the counties were located at $32^{\circ} 17^{\prime} \sim 34^{\circ} 18^{\prime}$ north latitude, $113^{\circ} \sim 117^{\circ} 09^{\prime}$ east longitude with malaria re-emergence in recent years.

\section{Sample collection}

A total of 187 blood samples from patients with acute $P$. vivax infections with signs and symptoms associated

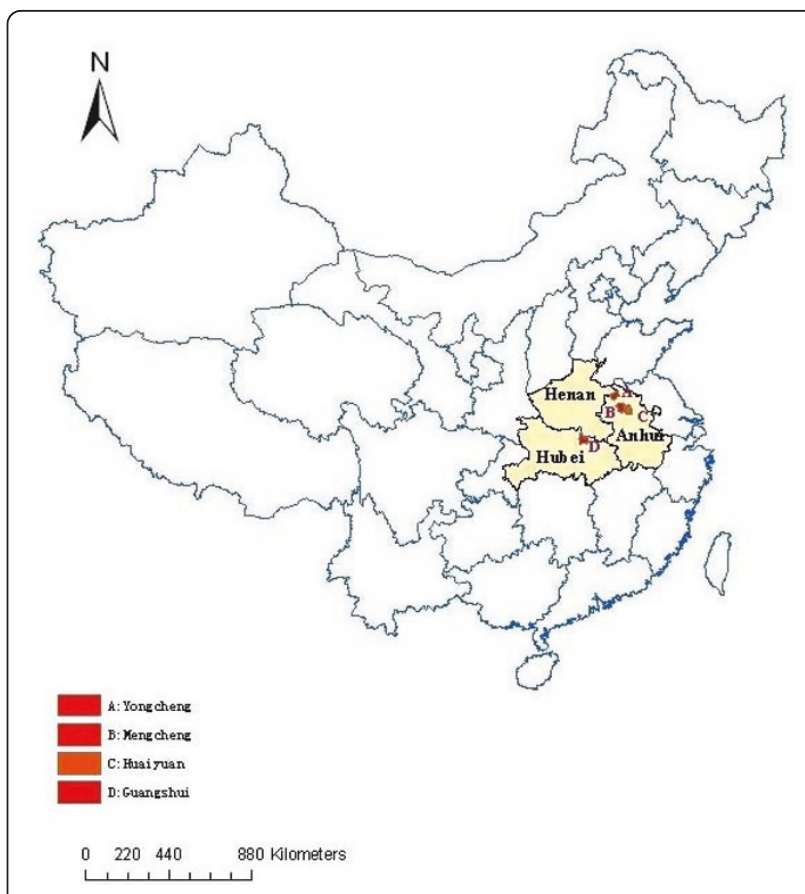

Figure 1 Map of distribution sentinel sites and mutant pvdhfr in Central China.

with malaria were collected from various clinics/hospitals in different geographical locations in Central China.

The diagnosis was made by microscopic examination of Giemsa-stained thin and thick blood smears, and then a multiplex PCR was performed to confirm the Plasmodium species. All the patients were found to be infected only with $P$. vivax. An additional drop of blood from finger pricked capillary blood was collected on $3 \mathrm{M}$ Whatman filter papers for storage and transport of infected blood samples after informed consent was obtained. The filter papers were thoroughly dried, sealed in a plastic bag with desiccant, and stored at $-20^{\circ} \mathrm{C}$.

All the blood samples were collected with the consent of each patient and approval of the protocol was obtained from the Institutional Research Ethical Committee prior to the study. Patients with a positive smear were treated with chloroquine (total of $25 \mathrm{mg} / \mathrm{kg}$ body weight in three divided daily doses) plus primaquine (total of $180 \mathrm{mg}$ in eight divided daily doses) according to national guideline for treatment of $P$. vivax infections.

\section{Parasite DNA extraction and amplification}

The filter papers were thoroughly rinsed in $500 \mu \mathrm{l}$ of sterile distilled water, placed in micro tube to which 50 $\mu \mathrm{l}$ of distilled water were added. DNA was extracted by Chelex method [21].

A multiplex PCR using conditions described previously [22] was performed to confirm the Plasmodium species in all isolates. 
Based on the complete $d h f r$-ts sequence (GenBank accession nos.98123), including 5-upstream non-coding region, the following primer pairs were designed for the nested PCR protocol: The primary amplification was performed using the external primers, VDT-OF (5'ATGGAGGACCTTTCAGATGTATTTGACATT-3') and VDT-OR (5'-GGCGGCCATCTCCATGGTTATTTTAT CGTG-3'), wherein the entire $P$. vivax dhfr-ts gene $(1.8 \mathrm{~kb})$ was amplified. This primary amplification product was then used for performing nested PCR to amplify $p v d h f r$ domain (711 bp). The oligonucleotide pair used was VDT-OF (5'-ATGGAGGACCTTTCAGATGTATTTGACATT-3') and VDFNR (5'-TCACACGGGTAGGCGCCGTTGATCCTCGTG-3').

The reaction mixture consisted of template DNA (10 $\mu \mathrm{l}$ of genomic DNA extracted from filter papers for the primary amplification and $1 \mu \mathrm{l}$ of the primary reaction for the secondary nested PCR), $15 \mathrm{pmol}$ of forward and reverse primers, buffer $(50 \mathrm{mM} \mathrm{KCl}, 10 \mathrm{mM}$ Tris, $\mathrm{pH}$ 8.3), $1.5 \mathrm{mM} \mathrm{MgCl}_{2}, 200 \mu \mathrm{M}$ deoxynucleoside triphosphates, and 1 unit of Taq DNA polymerase (Promega, USA) in a final volume of $50 \mu \mathrm{l}$. The PTC-100 thermal cycler (PTC-200, Bio-Rad, USA) was programmed as follows: $94^{\circ} \mathrm{C}$ for $2 \mathrm{~min}$ for the first cycle and $30 \mathrm{~s}$ in subsequent cycles, $50^{\circ} \mathrm{C}$ for $1 \mathrm{~min}$ for the first cycle and $30 \mathrm{~s}$ in subsequent cycles, and $72^{\circ} \mathrm{C}$ for $1 \mathrm{~min}$ for all cycles, for a total of 30 cycles, followed by a $15 \mathrm{~min}$ extension step at $72^{\circ} \mathrm{C}$. The amplified PCR products were then analyzed on $2 \%$ agarose gel, stained with ethidium bromide, and visualized under ultraviolet illumination. All the samples showed specific amplification in the present study.

\section{Sequence analysis}

The amplified products were purified from agarose gel and sequenced by automated DNA sequence (ABI systems, Perkin-Elmer, France). Sequence alignments and analysis was carried out using Mega and Bioedit software. Amino acid sequences were compared with wildtype sequences (GenBank accession nos.98123 for pvdhfr)

\section{Results}

\section{Malaria situation}

The malaria transmission in Central China was very low in 1990's, and malaria was basically eliminated in most areas with malaria incidence less than 1/10,000. However, early in the $21^{\text {th }}$ century, malaria has reemerged in these areas, especially the Anhui Province.

From Figure 2, malaria reemerged in Yongcheng, Mengcheng and Huaiyuan Counties from 2000 and the incidence of Yongcheng County was highest with $122.41 / 100,000$ in 2007 while malaria is relatively stable in Guangshui City. In these areas, there was a plain

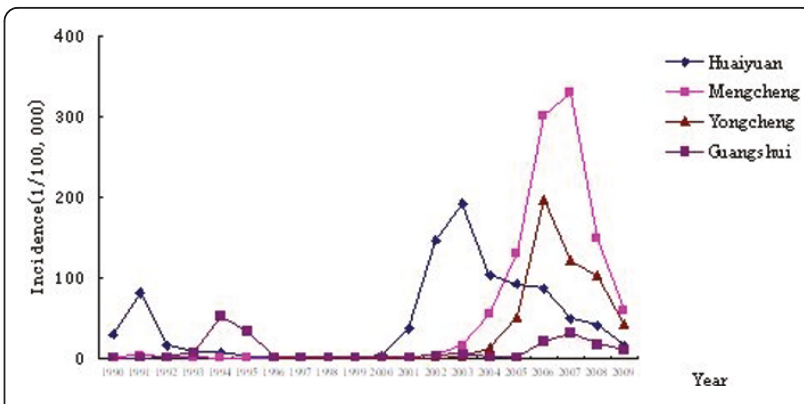

Figure 2 Malaria incidences in Huaiyuan, Mengcheng, Yongcheng and Guangshui Counties from year 1990 to 2009 from case report system.

landscape with soybean as the primary crop, and it was a fixed vectorial area, including $A n$. sinensis and $A n$. anthropophagus based on historical vectorial investigations in the Huang-Huai River region. The average vector capacity in this area was 0.1686 in 1990's.

Zhou [23] found that the spatial distribution between malaria cases and water-body, the changing of meteorological factors, and increasing vectorial capacity and basic reproductive rate of $A n$. sinensis lead to malaria re-emergence in these areas.

\section{Mutations in the pvdhfr gene}

Total of 187 samples were collected and all the samples were confirmed to be $P$. vivax by PCR (data not shown). Pvdhfr gene sequences from a total of 187 P. vivax samples were amplified by primary and nested PCR. Sequence polymorphism was assessed in $p v d h f r$ genes from 187 P. vivax samples. Compared with the wild-type sequence (GenBank accession nos.98123), $p v d h f r$ genes from the 187 samples had point mutations, among which three resulted in amino acid substitutions. No synonymous mutations were detected at positions 58, 61 and 117 , and the point mutation at codons 57 and 173 was not observed in the samples. The S117T mutation was the most prevalent (20.9\%), followed by the T61M mutation. Among all the samples, $21.4 \%$ were wild-type, whereas mutations were detected at three codons $(58,61$ and 117) including single mutant (34.8\%) and double mutants (43.8\%) without triple mutations. The proportions of wild type and mutant $p v d h f r$ alleles were different in different provinces (showed in Figure 3).

On the basis of amino acid changes, the pvdhfr sequences can be grouped into six alleles. Except for the wild-type allele, the most prevalent mutant allele was the one with double mutation at codons 58 and 117 (24.6\%). Three types of single mutation (S58R, T61M and $\mathrm{S} 117 \mathrm{~N}$ ) were found in $2.1 \%, 11.8 \%$ and $20.9 \%$ of parasite isolates, respectively. The four $P$. vivax parasite populations in Central China also differed in $p v d h f r$ allele frequencies (Table 1). 147 of 187 samples yielded 


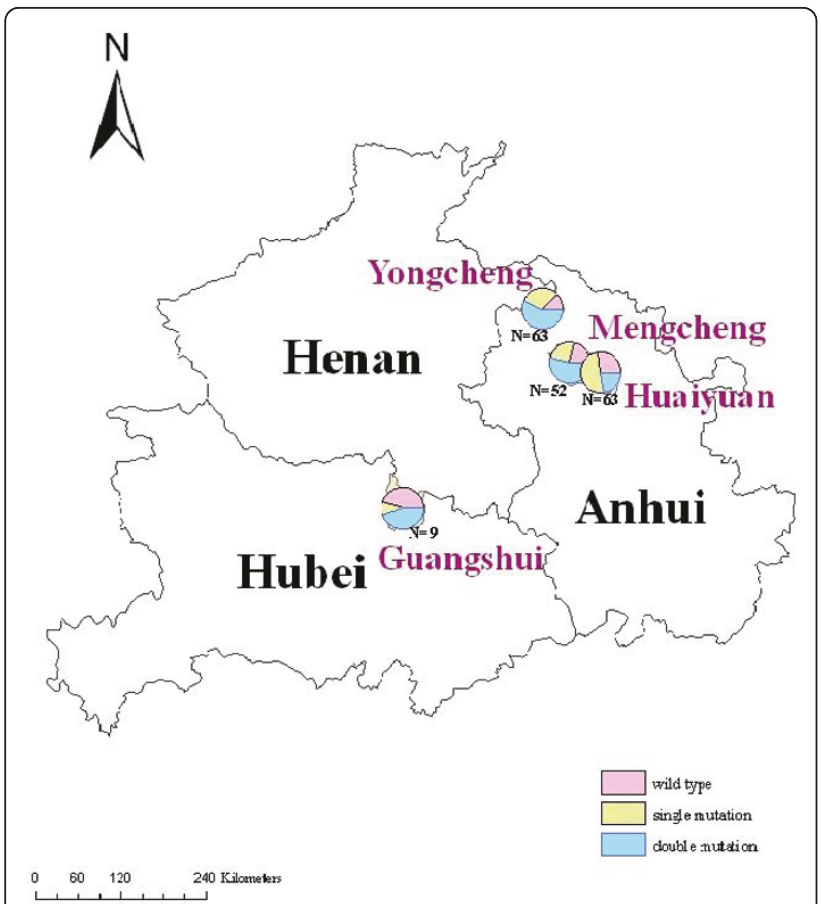

Figure 3 The Pie charts show the proportions of wild type and mutant pvdhfr alleles.

identical $d h f r$ sequence which was of mutant type. These isolates carried the key double mutations associated with pyrimethamine resistance, S58R and S117N, which correspond to Cys59Arg and Ser108Asn substitutions in $P$. falciparum, respectively.

These changes and corresponding positions of mutations observed in pvdhfr were shown in Table 1. Various numbers of wild-type alleles were identified from parasites originating from different regions with frequencies ranging from $12.7 \%$ to $44.4 \%$.

\section{Discussion}

In terms of morbidity, $P$. vivax infections account for a considerable part of malarial disease and economic burden in China and elsewhere in Southeast Asia, calling for increasing research effort to understand the epidemiology of $P$. vivax [2].

The current standard treatment of $P$. vivax for chloroquine-sensitive infections recommended by WHO is chloroquine $25 \mathrm{mg}$ base/ $\mathrm{kg}$ bw divided over 3 days, combined with primaquine $0.25 \mathrm{mg}$ base $/ \mathrm{kg}$ bw, taken with food once daily for 14 days to eliminate hypnozoites[24]. In China, the first line drugs for the current treatment of $P$. vivax are chloroquine plus primaquine and the total dosage of primaquine $(180 \mathrm{mg}$ dosage for 8 days) is different from WHO recommendation. The second line drugs was artemisinin combined therapy (ACT), which includes four types [25].
Table 1 Prevalence of pvdhfr mutant alleles in P.vivax isolates from Central China

\begin{tabular}{|c|c|c|c|c|c|c|}
\hline \multirow[t]{2}{*}{ Region } & \multicolumn{6}{|c|}{ Pvdfhr } \\
\hline & $\mathrm{N}(\%)$ & 57 & 58 & 61 & 117 & 173 \\
\hline Wild type & & $\mathrm{F}$ & $\mathrm{S}$ & $\mathrm{T}$ & $\mathrm{S}$ & 1 \\
\hline \multirow[t]{6}{*}{ Huaiyuan County } & $17(27.0)$ & $\mathrm{F}$ & $S$ & $\mathrm{~T}$ & $\mathrm{~S}$ & । \\
\hline & 0 & $\mathrm{~F}$ & $\mathrm{R}$ & $\mathrm{T}$ & $S$ & । \\
\hline & $9(14.3)$ & $\mathrm{F}$ & $\mathrm{S}$ & $M$ & $S$ & I \\
\hline & $23(36.5)$ & $\mathrm{F}$ & $\mathrm{S}$ & $\mathrm{T}$ & $N$ & । \\
\hline & 10(15.9) & $\mathrm{F}$ & $\mathrm{R}$ & $\mathrm{T}$ & N & । \\
\hline & $4(6.3)$ & $\mathrm{F}$ & $S$ & $M$ & N & । \\
\hline \multirow[t]{6}{*}{ Mengcheng County } & $11(21.2)$ & $\mathrm{F}$ & $\mathrm{S}$ & $\mathrm{T}$ & $S$ & I \\
\hline & $2(3.8)$ & $\mathrm{F}$ & $\mathrm{R}$ & $\mathrm{T}$ & $S$ & । \\
\hline & $4(7.7)$ & $\mathrm{F}$ & $S$ & $M$ & $S$ & । \\
\hline & $7(13.5)$ & $\mathrm{F}$ & S & $\mathrm{T}$ & $\mathrm{N}$ & I \\
\hline & 17(32.6) & $\mathrm{F}$ & $\mathrm{R}$ & $\mathrm{T}$ & $\mathrm{N}$ & । \\
\hline & $11(21.2)$ & $\mathrm{F}$ & $S$ & $M$ & N & 1 \\
\hline \multirow[t]{6}{*}{ Yongcheng County } & $8(12.7)$ & $\mathrm{F}$ & $S$ & $\mathrm{~T}$ & $S$ & I \\
\hline & $2(3.2)$ & $\mathrm{F}$ & $\mathrm{R}$ & $\mathrm{T}$ & $S$ & I \\
\hline & $9(14.3)$ & $\mathrm{F}$ & S & $M$ & $S$ & I \\
\hline & $8(12.7)$ & $\mathrm{F}$ & $S$ & $\mathrm{~T}$ & $\mathrm{~N}$ & I \\
\hline & 15(23.8) & $\mathrm{F}$ & $\mathrm{R}$ & $\mathrm{T}$ & N & I \\
\hline & $21(33.3)$ & $\mathrm{F}$ & $\mathrm{S}$ & $M$ & $\mathrm{~N}$ & I \\
\hline \multirow[t]{6}{*}{ Guangshui City } & $4(44.4)$ & $\mathrm{F}$ & $S$ & $\mathrm{~T}$ & $S$ & I \\
\hline & 0 & $\mathrm{~F}$ & $\mathrm{R}$ & $\mathrm{T}$ & $S$ & 1 \\
\hline & 0 & $\mathrm{~F}$ & $S$ & $M$ & S & 1 \\
\hline & $1(11.2)$ & $\mathrm{F}$ & $S$ & $\mathrm{~T}$ & N & 1 \\
\hline & $4(44.4)$ & $\mathrm{F}$ & $\mathbf{R}$ & $\mathrm{T}$ & $\mathrm{N}$ & I \\
\hline & 0 & $\mathrm{~F}$ & $S$ & $M$ & N & I \\
\hline Total & 187 & & & & & \\
\hline
\end{tabular}

Mutations in the $p v d h f r$ gene are known to be associated with resistance to antifolate drugs. Although antifolates were used to treat $P$. falciparum malaria, very little information was available about the origin and spread of this drug resistance in P. vivax. Allelic diversity at flanking microsatellite loci of the $d h f r$ gene will be helpful in understanding the origin and spread of antifolate resistance in P. vivax populations as well as the evolutionary history of the parasite species. Therefore, we planned to analyze the extent of these mutations in $P$. vivax populations in Central China, by isolating and sequencing the $d h f r$ gene for 187 P. vivax isolates originating from different geographical regions of Central China. This is the first study to investigate pvdhfr polymorphisms in Central China.

In the present study, we have analyzed $p v d h f r$ gene sequences from $187 P$. vivax isolates from different geographical regions in Central China (Figure 1). Analysis of $p v d h f r$ sequences showed limited polymorphism as compared to earlier studies. Approximately half of the P. vivax isolates obtained in Central China present the key double Arg-58/Asn-117 mutations in the dhfr gene 
and it is similar to that of the neighboring countries, Cambodia [26], Myanmar [15], Thailand [27] and Vietnam [28]. But we did not find triple and quadruple mutations just as that of recent study in China, Thailand, Vietnam and Korea [29,30]. Likewise, none of the Cambodia, Thailand, and Myanmar isolates studied had the mutant Leu-173, homologous to Ile164Leu substitution in the P. falciparum dhfr associated with a high level antifolate resistance. However, in contrast to Thailand isolates, which showed a high proportion (54\%) of mutant Leu-57, all isolates in our studies had the wild type Phe-57 codon.

Pyrimethamine was used for radical treatment of $P$. vivax combined with primaquine 40 years ago [unpublished data]. Also, pyrimethamine was added to salt for prophylaxis in 1980's. Pyrimethamine plus primaquine were recommended as prophylaxis of medicine for specific populations in China in 1980's [31]. Surprisingly, in our study there is a difference in $p v d h f r$ allele frequencies between the sentinel sites, but the reason was not clear. So far, no data is available on its susceptibility to pyrimethamine. There were different population structures and genetic polymorphisms in P.vivax and it could be postulated that they have a different susceptibility to pyrimethamine. Besides, it has been hypothesized that the S117N mutation represents the first step in the drug-resistance selection process that has occurred in the parasite [32].

For vivax malaria resistance in China, only one report showed the data of in vitro susceptibility to chloroquine of $P$. vivax isolate in Central China and the geometric mean IC50 of chloroquine was $63.23 \mathrm{nmol} / \mathrm{L}$ and although 6 isolates showed resistance to chloroquine in vitro, we cannot conclude that there was chloroquine resistance in China [33].

\section{Limitation}

Although our study showed that $P$. vivax in Central China may be relatively susceptible to pyrimethamine, it was not recommended in national antimalarial drug policy for the treatment or prophylaxis of vivax malaria treatment. A previous study [33] has found vivax isolates are resistant to chloroquine in vitro, therefore some related to chloroquine-resistance gene will be tested in the future.

\section{Conclusions}

However, from the molecular viewpoint, it is of interest to analyze, as in the case of $P$. falciparum, to what extent a molecular marker, or set of markers, can predict the parasitological and clinical outcome of antimalarial drug treatment. Further molecular characterization of $P$. vivax isolates from different endemic areas may be a useful alternative approach to establish the epidemiology of drug-resistant malaria.

\section{Acknowledgements and Funding}

This work is supported by the National S \& T Major Program (Grant No. 2008ZX10004-011)

\section{Author details}

${ }^{1}$ National Institute of Parasitic Diseases, Chinese Center for Disease Control and Prevention; WHO Collaborating Centre for Malaria, Schistosomiasis and Filariasia; Laboratory of Parasite and Vector Biology, Ministry of Health, Shanghai 200025, PR China. ${ }^{2}$ Department of Parasitology, Anhui Center for Disease Control and Prevention, Hefei 230061, PR China. ${ }^{3}$ Department of Parasitology, Henan Center for Disease Control and Prevention, Zhengzhou 450003, PR China.

\section{Authors' contributions}

$\mathrm{FH}$ and SSZ organized the survey, coordinated and supervised the sample collection, data entry and analysis. LHT helped in the study design and choice of study villages to be included in the trial and reviewed the manuscript. SSZ performed Parasite DNA amplification and the quality controls of all blood samples results. WDL and HWZ processed all the filte papers collection. All authors read and approved the final manuscript.

\section{Conflict of interests}

The authors declare that they have no competing interests.

Received: 15 March 2011 Accepted: 17 May 2011

Published: 17 May 2011

\section{References}

1. Price NRic, Tjitra Emiliana, Guerra ACarlos, Yeung Shunmay, White JNicholas, Anstey MNicholas: Vivax malaria: Neglected and not benign. Am J Trop Med Hyg 2007, 77:79-87.

2. Mendis K, Sina BJ, Marchesini P, Carter Richart: The neglected burden of Plasmodium vivax malaria. Am J Trop Med Hyg 2001, 64:97-106.

3. Zhou SS, Wang Y, Xia ZG: Malaria situation in the People's Republic of China in 2009. Chin Parasitol Parasit Dis 2011, 29:1-2.

4. Shuisen Zhou, Fang Huang, Linhua Tang, Xiang Zheng, Yuzu Shen, Yunpu Su, Guangquan Huang: Study on the spatial distribution of malaria in Yellow River and Huai River areas based on the "Kriging" method. Journal of Pathogen Biology 2007, 3:204-207.

5. Udomsangpetch R, Kaneko O, Chotivanich K, Sattabongkot J: Cultivation of Plasmodium vivax. Trends Parasitol 2008, 24:85-88.

6. Cowman AF: Molecular Genetics of Drug Resistance Amsterdam: Harwood Academic press; 1997.

7. de Pecoulas PE, Basco LK, Tahar R, Ouatas T, Mazabraud A: Analysis of the Plasmodium vivax dihydrofolate reductase-thymidylate synthase gene sequence. Gene 1998, 211:177-185.

8. Tahar R, de Pecoulas PE, Mazabraud A, Basco LK, de Pecoulas PE: Plasmodium vivax: rapid detection by polymerase chain reaction and restriction fragment length polymorphism of the key mutation in dihydrofolate reductase-thymidylate synthase gene associated with pyrimethamine resistance. Exp Parasitol 1998, 89:343-346.

9. Tahar R, Eldin de Pecoulas P, Basco LK, Chiadmi M, Mazabraud A: Kinetic properties of dihydrofolate reductase from wild-type and mutant Plasmodium vivax expressed in Escherichia coli. Mol Biochem Parasitol 2001, 113:241-249.

10. Kaur Suminder, Prajapati KSurendra, Kalyanaraman Kavitha, Mohmmed Asif, Joshi Hema, Chauhan SVirander: Plasmodium vivax dihydrofolate reductase point mutations from the Indian subcontinent. Acta Tropica 2006, 97:174-180.

11. Picot S, Brega S, Gerome P, Velut G, de Monbrison F, Cheminelb V, Peyrona F: Absence of nucleotide polymorphism in a Plasmodium vivax multidrug resistance gene after failure of mefloquine prophylaxis in French Guyana. Tran R Soc Trop Med Hyg 2005, 99:234-237.

12. Barnadas Céline, Tichit Magali, Bouchier Christiane, Ratsimbasoa Arsène, Randrianasolo Laurence, Raherinjafy Rogelin, Jahevitra Martial, 
Picot Stéphane, Ménard Didier: Plasmodium vivax dhfr and dhps mutations in isolates from Madagascar and therapeutic response to sulphadoxine-pyrimethamine. Malar J 2008, 7:35.

13. De-Pecoulas PE, Tahar R, Ouatas T, Mazabraud A, Basco LK: Sequence variations in the Plasmodium vivax dihydrofolate reductase-thymidylate synthase gene and their relationship with pyrimethamine resistance. Mol Biochem Parasitol 1998, 92:265-273.

14. Imwong M, Pukrittayakamee S, Renia L, Letourneur F, Charlieu JP, Leartsakulpanich U, Looareesuwan S, White NJ, Snounou G: Novel point mutations in the dihydrofolate reductase gene of Plasmodium vivax: evidence for sequential selection by drug pressure. Antimicrob Agents Chemother 2003, 47:1514-1521.

15. Imwong M, Pukrittakayamee S, Looareesuwan S, Pasvol G, Poirreiz J, White NJ, Snounou G: Association of genetic mutations in Plasmodium vivax $\mathrm{dhfr}$ with resistance to sulfadoxine-pyrimethamine: geographical and clinical correlates. Antimicrob Agents Chemother 2001, 45:3122-3127.

16. Hastings MD, Porter KM, Maguire JD, Susanti I, Kania W, Bangs MJ, Hopkins SC, Baird JK: Dihydrofolate reductase mutations in Plasmodium vivax from Indonesia and therapeutic response to sulfadoxine plus pyrimethamine. J Infect Dis 2004, 189:744-750.

17. Tjitra E, Baker J, Suprianto S, Cheng Q, Anstey NM: Therapeutic efficacies of artesunate-sulfadoxine-pyrimethamine and chloroquine-sulfadoxinepyrimethamine in vivax malaria pilot studies: relationship to Plasmodium vivax dhfr mutations. Antimicrob Agents Chemother 2002, 46:3947-3953.

18. Xu BL, Su YP, Shang LY, Zhang HW: Malaria control in Henan Province, People's Republic of China. Am J Trop Med Hyg 2006, 74:564-567.

19. Zhang W, Wang L, Fang L, Ma J, Xu Y, Jiang J, Hui F, Wang J, Liang S, Yang $\mathrm{H}$, Cao W: Spatial analysis of malaria in Anhui province, China. Malar J 2008, 7:206.

20. Baird JK: Chloroquine resistance in Plasmodium vivax. Antimicrob Agents Chemother 2004, 48:4075-4083.

21. Bereczky SÁndor, Andreas MÅrtensson, Gil J Pedro, Anna FÄrnert: Short report: Rapid DNA extraction from archive blood spots on filter paper for genotyping of Plasmodium falciparum. Am J Trop Med Hyg 2005, 72:249-251.

22. Padley D, Moody AH, Chiodini PL, Saldanha J: Use of a rapid, single-round, multiplex PCR to detect malarial parasites and identify the species present. Ann Trop Med Parasitol 2003, 97:131-137.

23. Zhou SShui, Huang Fang, Wang JJian, Zhang SShao, Su PYun, Tang HLin: Geographical, meteorological and vectorial factors related to malaria reemergence in Huang-Huai River of central China. Malar J 2010, 9:337.

24. World Health Organization: Guidelines for malaria treatment., second [http://whqlibdoc.who.int/publications/2010/9789241547925_eng.pdf].

25. Ministry of Health of the People's Republic of China: Technique plan for malaria control and prevention in China. 2007.

26. de Pécoulas Eldin Philippe, Tahar Rachida, Yi Poravuth, Thai Heng Khieng, Basco KLeonardo: Genetic variation of the dihydrofolate reductase gene in Plasmodium vivax in Snoul, northeastern Cambodia. Acta Tropica 2004, 92:1-6.

27. Rungsihirunrat Kanchana, Sibley Hopkins Carol, Mungthin Mathirut, NaBangchang Kesara: Geographical Distribution of Amino Acid Mutations in Plasmodium vivax DHFR and DHPS from Malaria Endemic Areas of Thailand. Am J Trop Med Hyg 2008, 77:79-87.

28. Auliff Al Yson, Wilson WDanny, Russell Bruce, Gao Qi, Chen Nanhua, Anh Le Ngoc, Maguire Jason, Bell David, O'neil TMichael, Cheng Qin: Amino acid mutations in Plasmodium vivac dhfr and dhps from several geographical regions and susceptibility to antifolate drugs. Am J Trop Med Hyg 2006, 75:617-621.

29. Miao M, Zhaoging Y, Long C, Jessica A, Yaming H, Liwang C: Different allele prevalence in the dihydrofolate deductase and dihydropteroate synthase genes in Plasmodium vivax populations from China. Am J Trop Med Hyg 2010, 83:1206-1211.

30. Feng L, Chae SL, Deok HN, Kwonkee K, Khin L, Tong SK, Hyeong WL, Junhu C, Yue W, Jestsumon S, Eun TH: Mutations in the antifolateresistance-associated gened dihydrofolate reductase and dihydropteroated synthase in Plasmodium vivax isolates from malariaendemic countries. Am J Trop Med Hyg 2010, 83:474-479.

31. Wang RZ: Efficiency of pyrimethamine salt for $P$. vivax prophylaxis. Railway Medicine 1981, 4:246-247.

32. Brega S, de Monbrison F, Severini C, Udomsangpetch R, Sutanto I, Ruckert P, Peyron F, Picot S: Real-time PCR for dihydrofolate reductase gene single-nucleotide polymorphisms in Plasmodium vivax isolates. Antimicrob Agents Chemother 2004, 48:2581-2587.

33. Lu F, Gao Q, Xia H, Tao ZY, Cao J, Gu YP, Zhou HY, Jin XL, Rachanee US, Jetsumon S: In vitro sensitivity test of Plasmodium vivax to chloroquine in center part of China. Chin J Schisto Control 2006, 18:265-267.

doi:10.1186/1756-3305-4-80

Cite this article as: Huang et al:: Monitoring resistance of Plasmdium vivax: Point mutations in dihydrofolate reductase gene in isolates from Central China. Parasites \& Vectors 2011 4:80.

\section{Submit your next manuscript to BioMed Central and take full advantage of:}

- Convenient online submission

- Thorough peer review

- No space constraints or color figure charges

- Immediate publication on acceptance

- Inclusion in PubMed, CAS, Scopus and Google Scholar

- Research which is freely available for redistribution

Submit your manuscript at www.biomedcentral.com/submit
Ciomed Central 